\title{
Estudo soroepidemiológico da infecção por Toxoplasma gondii em suínos e frangos, para abate, em região rural do Rio de Janeiro
}

\section{Epidemiological study of infection by Toxoplasma gondii in slaughterhouse swines and chickens from rural area in Rio de Janeiro}

\author{
Isabel Cristina Fábregas Bonna, ${ }^{*}$ Fabiano Borges Figueiredo, ${ }^{* *}$ Tatiana da Costa, ${ }^{* *}$ Regiane Trigueiro Vicente, ${ }^{* * *}$ \\ Charles André D. Santiago, ${ }^{* * * *}$ José Leonardo Nicolau, ${ }^{* * *}$ Leandro Batista das Neves, ${ }^{* * *}$ Patrícia Riddell Millar, ${ }^{* * * * *}$ \\ Leila Gatti Sobreiro, ${ }^{* * * * *}$ Maria Regina Reis Amendoeira ${ }^{* * *}$
}

\section{Resumo}

A prevalência da infecção por Toxoplasma gondii em animais de regiões rurais é um importante indicador tanto do risco de transmissão para humanos como da presença de oocistos do protozoário no ambiente. Com o objetivo de conhecer a prevalência e analisar as principais variáveis de importância clínica-epidemiológica da infecção por Toxoplasma gondii em suínos e frangos no bairro de Santa Rita de Cássia, Barra Mansa, RJ, foi feito um estudo seccional soroepidemiológico. Dos proprietários entrevistados, mais de $85 \%$ criavam estes animais para o consumo da família. Foram analisados os soros de 38 suínos e 316 frangos pela Reação de Imunofluorescência Indireta. A freqüência de anticorpos (lgG) anti-T. gondii em suínos foi de $65,8 \%$ e em frangos de $47,8 \%$. A presença de roedores e de gatos, em ambas as criações, foram estatisticamente associadas $\left(X^{2}: p<0,05\right)$ com a soropositividade para a infecção pelo protozoário. Nos suínos, foi também observada a associação do sexo $\left(X^{2}: p<0,05\right)$ com a presença de anticorpos anti- $T$. gondii. Outras variáveis também foram estudadas, como vacinação, condições das criações, exame clínico e procedência dos animais, demonstrando a necessidade de assistência médica veterinária, da implantação de ações profiláticas e, principalmente, a carência de medidas informativas para a população na região.

Palavras-chave: suínos, Gallus gallus, epidemiologia, Toxoplasma gondii.

\begin{abstract}
The prevalence of infection by T. Gondii in animals from rural area is an important indicator both of the risk of human infection and the presence of oocysts in the environment. A Serum-epidemiological Seccional Study was carried out in order to determine the prevalence and analyse the major variables of importance in the epidemiology of $T$. gondii infection in swines and chickens in Santa Rita de Cássia, Barra Mansa, RJ. Among the interviewed owners, more than $85 \%$ raised these animals for the consumption of the family. Serum samples were collected from 38 swines and 316 chickens and analysed through the Indirect Fluorescent Antibody Test. In swines the presence of antibody (IgG) anti-T. gondii was $65.8 \%$ and in chickens, the prevalence was $47.8 \%$. The presence of rodents and cats, in both breedings, had statistic association $\left(X^{2}: p<0.05\right)$ with the seroreactivity of the infection of the protozoario. In swines the sex was also significant $\left(X^{2}: p<0.05\right)$ to the presence of antibody anti-T. Gondii. Other variables had been studied as well, such as vaccination, breeding conditions, clinical examination and origin of the animals, demonstrating the necessity of veterinary medical assistance and the implantation of prophylactic actions, but mainly the lack of informative measures directed to the local population.
\end{abstract}

Keywords: swines, Gallus gallus, epidemiology, Toxoplasma gondii.

\section{Introdução}

O agente etiológico da toxoplasmose, Toxoplasma gondii, vem sendo encontrado em diversas espécies de animais, inclusive no homem, por inúmeros pesquisadores. Em 1939, estudos da identidade biológica e imunológica dos isolados de diferentes hospedeiros concluíram que os isolados não eram espécie-específica, portanto, se tratava de uma única espécie, o T. gondii (Sabin, 1939).

A toxoplasmose é uma zoonose de alta prevalência e ampla distribuição geográfica. O T. gondii, parasita heteroxênico

\footnotetext{
* Programa de Pós-Graduação em Pesquisa Clínica e Doenças Infecciosas (Doutorado) do Instituto de Pesquisa Clínica Evandro Chagas, FIOCRUZ.

** Médico Veterinário do Centro de Zoonoses do IPEC, FIOCRUZ, RJ.

*** Departamento de Protozoologia, Laboratório de Toxoplasmose, Instituto Oswaldo Cruz - FIOCRUZ, Rio de Janeiro, RJ, Brasil.

**** Médico-veterinário, Vigilância Sanitária da Prefeitura de Barra Mansa, RJ.

***** Programa de Pós-Graduação em Medicina Veterinária (Doutorado), Higiene Veterinária e Processamento Tecnológico de Produtos de Origem animal, Universidade Federal Fluminense.

***** Departamento de Saúde Coletiva Veterinária e Saúde Pública - Faculdade de Veterinária, Universidade Federal Fluminense. Autor para correspondência: Patrícia Riddell Millar. E-mail: patriciarm79@yahoo.com.br
} 
facultativo e intracelular obrigatório, possui um complexo ciclo biológico com três principais formas evolutivas - taquizoítas, bradizoítas e oocistos (Krick e Remington, 1978). A grande dispersão do parasita pode ser determinada pela sua possibilidade em apresentar vários mecanismos de transmissão, como a ingestão acidental de oocistos, a manipulação de terra contaminada com oocistos, a ingestão de carne crua ou malcozida contaminada com cistos (Amendoeira et al., 2003) e pela passagem via transplacentária de taquizoítas (Ambroise-Thomas e Pelloux, 1993; Tenter et al., 2000).

Os bradizoítas são encontrados no interior de cistos teciduais alojados em diferentes tecidos dos hospedeiros intermediários, principalmente em musculatura cardíaca, esquelética e tecido nervoso (Krick e Remington, 1978). Nos hospedeiros definitivos, os felídeos (gêneros: Lynx e Felis), ocorre o ciclo sexuado do parasita e a formação dos oocistos imaturos, que ao serem eliminados com as fezes dos gatos, contaminam o ambiente, onde se tornam infectantes e podem ficar viáveis por mais de um ano, em condições climáticas favoráveis (Amendoeira, 1995; Remington e Klein, 2001).

Os animais são considerados fonte de infecção para os humanos, quando associados ao hábito de ingerir carne crua ou malcozida (Tenter et al., 2000). Os suínos adquirem a toxoplasmose pela ingestão de água e ração contaminadas com oocistos presentes nas fezes de felinos, cistos em roedores, carnes ou restos de alimentos infectados, ou por infecção transplacentária (Smith et al. 1991; Araújo, 1999).

O consumo de carne suína, crua ou malcozida, é uma importante fonte de transmissão do protozoário para os humanos. O levantamento sorológico da infecção por T. gondii, nessa espécie de animal, se torna fundamental para avaliar o grau de exposição, a este agente, de consumidores de carne e seus derivados (Fialho e Araújo, 2002).

Existem poucos estudos evidenciando o papel de Gallus gallus na transmissão do T.gondii. Sabe-se que esses animais representam um risco de infecção para o homem, principalmente quando estes manipulam carnes in natura sem muita higiene, por meio do consumo de carnes cruas ou mal cozidas, ou mesmo por meio do consumo de ovos crus (Amendoeira, 1995; Garcia et al., 2000).

A soroprevalência da infecção por T. gondii, em animais, pode ser um bom parâmetro para a sinalização do problema em regiões rurais, pois estes estão em contado direto com o ambiente. A infecção por T. gondiie a toxoplasmose despertam interesse em diversas áreas da pesquisa. Em medicina veterinária envolvem três principais aspectos: I- Clínico, que diminui a qualidade de vida dos animais acometidos; IIEpidemiológico, por ser uma zoonose e III- Econômico, com a ocorrência de abortos, perda de animais e gastos com medicamentos em animais de produção. Por esses motivos, que apesar de complexa, a profilaxia é fundamental e para que esta seja eficaz, é importante conhecer as características ambientais e da população.

Com o objetivo de analisar a prevalência da presença de anticorpo lgG anti-T. gondii em soros de suínos e frangos, criados e abatidos para o consumo humano, foi feito um inquérito soroepidemiológico, com a abordagem das principais variáveis de interesse na epidemiologia da toxoplasmose. Este estudo foi realizado em uma região rural do Rio de Janeiro, com uma alta prevalência de toxoplasmose humana $(67,2 \%)$.

\section{Material e métodos}

Este projeto foi avaliado e aprovado pelo Comitê de Ética na Utilização de Animais - CEUA, Fiocruz, sob o no P0280-06. Foi feito um estudo seccional dos suínos e dos frangos no bairro de Santa Rita de Cássia, Barra Mansa, RJ. Os proprietários assinaram o Termo de Consentimento Livre e Esclarecido e preencheram um questionário epidemiológico, junto com um membro da equipe. Após a assinatura, foram feitos o exame clínico e a coleta de sangue dos animais. Foram coletadas 38 amostras de sangue de suínos e 316 amostras de frangos da região, em tubo sem anticoagulante, para a realização da Reação de Imunofluorescência Indireta (RIFI) no Laboratório de Toxoplasmose, Departamento de Protozoologia do Instituto Oswaldo Cruz IOC/FIOCRUZ. A RIFI foi desenvolvida de acordo com a metodologia proposta por Goldman (1957) e modificada por Camargo (1974). As variáveis individuais (sexo, idade, condição geral do animal, procedência do animal e vacinação) e epidemiológicas (tipo de alimentação, viver solto ou confinado, condições do plantel e presença de felinos e roedores nas criações) foram descritas e analisadas pelo teste estatístico não paramétrico qui-quadrado $\left(\mathrm{X}^{2}\right)$ adotando á $=5 \%$.

\section{Resultados}

Todas as criações, tanto de suínos quanto de frangos, eram feitas no quintal das casas e destinadas ao abate para o consumo humano. Ao exame clínico não foi constatado nenhum sinal ou sintoma sugestivos de infecção. Como demonstrado na Tabela 1, nos animais estudados foi encontrada uma prevalência de $49,7 \%$ para a presença de anticorpos IgG anti- T. gondii.

Nas criações dos suínos, foi observado que cinco $(13,2 \%)$ animais apresentavam estado físico geral regular, 23,7\% eram castrados, 92,1\% não haviam recebido nenhum tipo de vacinação, todos os animais eram mantidos confinados em instalações próximas às residências. Não foram relatados casos de aborto espontâneo e nem de atraso de cio. Os animais, na maioria, eram nascidos na região $(73,7 \%)$, o restante era trazido de bairros vizinhos $(26,3 \%)$.

Tabela 1: Prevalência de anticorpos (lgG) anti-T. gondii na Reação de Imunofluorescência Indireta (RIFI), em suínos e frangos, criados para abate no Bairro de Santa Rita de Cássia, Barra Mansa, RJ.

\begin{tabular}{ccccccc}
\hline \hline \multirow{2}{*}{ Espécies } & \multicolumn{3}{c}{ Resultado da RIFI - IgG } & \multicolumn{2}{c}{ Total } \\
\cline { 2 - 6 } & \multicolumn{2}{c}{ Positivo } & \multicolumn{2}{c}{ Negativo } & & \\
\cline { 2 - 6 } & $\mathbf{n}^{\star}$ & $\%$ & $\mathbf{n}^{\star}$ & $\%$ & $\mathbf{n}^{*}$ & $\%$ \\
\hline Suínos & 25 & 65,8 & 13 & 34,2 & 38 & 100,0 \\
Frangos & 151 & 47,8 & 165 & 52,2 & 316 & 100,0 \\
Suínos/Frangos & 176 & 49,7 & 178 & 50,3 & 354 & 100,0 \\
\hline \hline
\end{tabular}

${ }^{*} n$ = número de animais; $p<0,05$

A prevalência de anticorpos IgG anti-T.gondii em suínos foi de $65,8 \%$ (Tabela 1). A maior freqüência $(47,4 \%)$ foi de títulos baixos, iguais ou inferiores a 1:64 (Tabela 2). Das residências com criações de suínos, $86,8 \%$ criam estes animais para consumo da família. A presença de roedores e gatos nas residências está significativamente associada $\left(X^{2}: p<0,05\right)$ à presença de anticorpos IgG anti-T. gondii, nos soros de suínos na RIFI. 
Tabela 2: Distribuição da titulação de anticorpos (lgG) anti-T. gondii, na reação de imunofluorescência indireta (RIFI), de 38 suínos criados para abate do bairro de Santa Rita de Cássia, Barra Mansa, RJ.

\begin{tabular}{ccc}
\hline \hline Títulos de IgG - Suínos & \multicolumn{2}{c}{ Freqüência } \\
\cline { 2 - 3 } RIFI & $\mathbf{n}^{*}$ & $\%$ \\
\hline NR & 13 & 34,2 \\
$\mathbf{1 : 1 6}$ & 09 & 23,7 \\
$\mathbf{1 : 6 4}$ & 09 & 23,7 \\
$\mathbf{1 : 2 5 6}$ & 02 & 5,3 \\
$\mathbf{1 : 1 0 2 4}$ & 05 & 13,2 \\
$\mathbf{1 : 4 0 9 6}$ & 00 & 0,0 \\
Total & 38 & 100,00 \\
\hline \hline
\end{tabular}

${ }^{*} n$ = número de animais; $p<0,05$

$\mathrm{Na}$ análise da distribuição dos suínos por sexo (Tabela 3) foi demonstrada a associação $\left(X^{2}: p<0,05\right)$ com a presença de anticorpos IgG anti- T. gondii, nesta região. Não houve diferença relevante da idade $\left(X^{2}: p>0,05\right)$ com a presença de anticorpos IgG anti- $T$. gondii, provavelmente por estes animais serem abatidos ainda muito jovens.

Nas criações de frangos (Gallus gallus) foi identificada uma prevalência de $47,8 \%$ de anticorpos IgG anti-T. gondii, na RIFI (Tabela 1). Ao exame clínico foi observado que $97,2 \%$ dos animais apresentavam bom estado físico geral, 42,4\% viviam soltos e a maioria tinha infestação por ectoparasitos $(56,3 \%$ infestados com piolhos, $1,3 \%$ com sarna). Todas as criações recebiam restos de comida humana para a alimentação, principalmente hortaliças. Nenhum animal era vacinado e $97,8 \%$ nasceram na região, sendo o restante proveniente de bairros próximos.

A maioria dos frangos $(44,3 \%)$ apresentou títulos iguais ou inferiores a 1:256, na RIFI (Tabela 4). Das residências estudadas, $91,1 \%$ e $75,6 \%$ dos proprietários relataram a presença de roedores e de gatos nos quintais, respectivamente. Mais de $90 \%$ dos proprietários entrevistados consomem a carne e os ovos destes animais.

O sexo $(p=0,624 ; p>0,05)$ e a característica de viver solto $(p=0,109 ; p>0,05)$, nos frangos, não estão associados à presença de anticorpos (IgG) anti-T. gondii na RIFI. Porém, como demonstrado nas Tabelas 5 e 6 , a presença de roedores e gatos nas residências está significativamente associada à presença de anticorpos IgG anti-T. gondii $\left(\mathrm{X}^{2}: \mathrm{p}<0,05\right)$, nos soros de frangos na RIFI.

A elevada prevalência de sororreagentes, em suínos e frangos, pode ser explicada pela característica rural da região, cuja base da economia é a horticultura, onde todos os proprietários alimentavam sua criações com restos de hortaliças e água de mina, sem tratamento. Além disso, os suínos também eram alimentados com restos de carnes cruas e os frangos têm um intenso contato com o ambiente, ciscando em terrenos com a presença de gatos.

\section{Discussão e conclusão}

Vários estudos, no Brasil e em outros países, têm como objetivo conhecer a soroprevalência da infecção por T. gondii em diversas espécies de animais e no homem. A prevalência de anticorpos IgG anti-T. gondii em suínos do bairro de Santa Rita de Cássia, região rural do Rio de Janeiro foi de $65,8 \%$, com uma maior ocorrência de títulos baixos de IgG compatível com infecção crônica. A freqüência de sororreagentes em
Tabela 3: Distribuição por sexo e a correlação com os resultados da reação de imunofluorescência indireta (RIFI) para a presença de anticorpo IgG anti- T. gondii em 38 suínos do bairro de Santa Rita de Cássia, Barra Mansa, RJ

\begin{tabular}{ccccccc}
\hline \hline \multirow{2}{*}{ Sexo } & \multicolumn{3}{c}{ Resultado da RIFI - IgG } & \multicolumn{2}{c}{ Total } \\
\cline { 2 - 5 } & \multicolumn{2}{c}{ Positivo } & \multicolumn{2}{c}{ Negativo } & & \\
\cline { 2 - 5 } & $\mathbf{n}^{\star}$ & $\%$ & $\mathbf{n}^{*}$ & $\%$ & $\mathbf{n}^{\star}$ & $\%$ \\
\hline Macho & 07 & 18,4 & 08 & 21,1 & 15 & 39,5 \\
Fêmea & 18 & 47,4 & 05 & 13,2 & 23 & 60,6 \\
Total & 25 & 65,8 & 13 & 34,2 & 38 & 100,0 \\
\hline \hline
\end{tabular}

${ }^{*} \mathrm{n}=$ número de animais; $\mathrm{p}<0,05$

Tabela 4: Distribuição da titulação de anticorpos (lgG) anti-T. gondii na reação de imunofluorescência indireta (RIFI) de 316 frangos (Gallus gallus) criados para abate do bairro de Santa Rita de Cássia, Barra Mansa, RJ

\begin{tabular}{ccc}
\hline \hline Títulos de IgG - Gallus domesticus & \multicolumn{2}{c}{ Freqüência } \\
\cline { 2 - 3 } RIFI & $\mathbf{n}^{*}$ & $\%$ \\
\hline NR & 165 & 52,2 \\
$\mathbf{1 : 1 6}$ & 55 & 17,4 \\
$\mathbf{1 : 6 4}$ & 41 & 13,0 \\
$\mathbf{1 : 2 5 6}$ & 44 & 13,9 \\
$\mathbf{1 : 1 0 2 4}$ & 11 & 3,5 \\
$\mathbf{1 : 4 0 9 6}$ & 00 & 0,0 \\
Total & 316 & 100,0 \\
\hline \hline
\end{tabular}

" $\mathrm{n}=$ número de animais

Tabela 5: Análise da distribuição de 316 frangos (Gallus gallus) quando a prevalência de anticorpos IgG anti-T. gondii na reação de imunofluorescência indireta (RIFI) em relação à presença de roedores nas criações do bairro de Santa Rita de Cássia, Barra Mansa, RJ

\begin{tabular}{ccccccc}
\hline \hline \multirow{2}{*}{$\begin{array}{c}\text { Presença de } \\
\text { roedores }\end{array}$} & \multicolumn{2}{c}{ Resultado da RIFI - IgG } & \multicolumn{2}{c}{ Total } \\
\cline { 2 - 5 } & \multicolumn{2}{c}{ Positivo } & \multicolumn{2}{c}{ Negativo } & & \\
\cline { 2 - 5 } & $\mathbf{n}^{*}$ & $\%$ & $\mathbf{n}^{*}$ & $\%$ & $\mathbf{n}^{*}$ & $\%$ \\
\hline Sim & 132 & 156 & 288 & \\
Não & 19 & 09 & 28 & \\
Total & 151 & 165 & 316 & 100,0 \\
\hline \hline
\end{tabular}

${ }^{*} \mathrm{n}=$ número de animais; $\mathrm{p}<0,05$

Tabela 6: Análise da distribuição de 316 frangos (Gallus gallus) quando a prevalência de anticorpos IgG anti- $T$. gondii na reação de imunofluorescência indireta (RIFI) em relação à presença de gatos nas criações do bairro de Santa Rita de Cássia, Barra Mansa, RJ

\begin{tabular}{ccccccc}
\hline \hline \multirow{2}{*}{$\begin{array}{c}\text { Presença de } \\
\text { gatos }\end{array}$} & \multicolumn{4}{c}{ Resultado da RIFI - IgG } & \multicolumn{2}{c}{ Total } \\
\cline { 2 - 5 } & \multicolumn{2}{c}{ Positivo } & \multicolumn{2}{c}{ Negativo } & & \\
\cline { 2 - 6 } & $\mathbf{n}^{\star}$ & $\%$ & $\mathbf{n}^{\star}$ & $\%$ & $\mathbf{N}^{\star}$ & $\%$ \\
\hline Sim & 123 & 38,9 & 116 & 36,7 & 239 & 75,6 \\
Não & 28 & 8,9 & 49 & 15,5 & 77 & 24,4 \\
Total & 151 & 47,8 & 165 & 52,2 & 316 & 100,0 \\
\hline \hline
\end{tabular}

${ }^{*} \mathrm{n}=$ número de animais; $\mathrm{p}<0,05$ 
Santa Rita de Cássia foi mais elevada do que em outras regiões, como a detectada na região rural do Amazonas, que foi de 43,7\% (Cavalcante et al., 2006), no Grande Porto Alegre de $33,75 \%$ (Fialho e Araujo, 2003), em São Paulo de 29,72\% (Barci et al., 1998), no Paraná de 24\% (Garcia et al., 1999) e em fazendas argentinas de 37,8\% (Venturini et al., 2004).

Em frangos, a soroprevalência $(47,8 \%)$, na região estudada está na média das relatadas em outras regiões do Brasil, como no estado do Pará e do Rio Grande do Sul, que foi de 46,4\% (Dubey et al., 2006) e na Argentina de 65,5\% (Dubey et al., 2003).

A carne crua ou malcozida de frangos e suínos, assim como de outros animais, é uma relevante fonte de infecção de T. gondii ao homem, tendo sido isolado de diversos tecidos (Dubey et

\section{Referências}

AMBROISE-THOMAS, P.; PELLOUX, H. Toxoplasmosis-congenital and in immunocompromissed patients: a parallel. Parasitology Today. v. 9, p. 61-63, 1993.

AMENDOEIRA, M.R.R. Mecanismos de transmissão da toxoplasmose. Anais da Academia Nacional de Medicina, Rio de Janeiro, v. 155, n. 4, p.224-225, 1995.

AMENDOEIRA, M.R.R.; SOBRAL, C.A.Q.; TEVA, A. LIMA, J.N., KLEIN, C.H. Inquérito soroloógico para a infecção por Toxoplasma gondii em ameríndios isolados, Mato Grosso. Revista da Sociedade Brasileira de Medicina Tropical, Uberaba, v. 36, n. 6, p. 671-676, 2003.

ARAÚJO, F.A.P. Avaliação soroepidemiológica de anticorpos para Toxoplasma gondii, Nicolle \& Manceuax, 1909 em soros de suínos (Sus scrofa) da região da grande Erechim, RS - Brasil, detectados através das técnicas de imunofluorescência indireta e imunoenzimática. Rio de Janeiro, 1999. 143 f. Tese (Doutorado em Biologia Parasitária). Instituto Oswaldo cruz, Rio de Janeiro,1999.

BARCI, L. A. G. Freqüência de anticorpos anti-Toxoplasma gondiiem plantéis de suínos reprodutores no estado de São Paulo, Brasil. Arquivos do Instituto Biológico, v. 65, n. 1, p. 111-113. 1998.

CAMARGO, M.E. Introdução às técnicas de imunofluorescência. Revista Brasileira de Patologia Clínica. v. 10, p. 87-107, 1974.

CAVALCANTE, G.T.; AGUIAR, D.M.; CHIEBAO, D.; DUBEY, J.P.; RUIZ, V.L.A.; DIAS, R.A.; CAMARGO, L.M.A.; LABRUNA, M.B.; GENNARI, S.M. Seroprevalence of Toxoplasma gondii antibodies in cats and pigs from rural western Amazon, Brazil. Journal of Parasitology, v. 92, n. 4, p. 863-864, 2006.

DIAS R.A.F.; NAVARRO I.T.; RUFFOLO, B.B.; BUGNI F.M.; CASTRO, M.V.; FREIRE R.L. Toxoplasma gondii in fresh pork sausage and seroprevalence in butchers from factories in Londrina, Paraná State, Brazil. Revista do Instituto de Medicina Tropical de São Paulo, v. 47, n. 4, p. 185-189, 2005.

DUBEY, J.P.; FRENKEL, J.K. Cyst-induced toxoplasmosis in cats. Journal Protozoology. v. 19, n. 1, p. 177-80, 1992.

DUBEY, J.P;GRAHAM, D.H.;BLACKSTON, C.R.;LEHMANN, T.; GENNARI, S.M.; RAGOZO, A.M.A.; NISHI, S.M.; SHEN, S.K.; HILL, D.E.; THULLIEZ, P. Biological and genetic characterisation of Toxoplasma gondiiisolates from chickens (Gallus domesticus) from São Paulo, Brazil: unex pected findings. International Journal for Parasitology. v. 32, p. 99-105, 2002. DUBEY, J.P; SUNDAR, N.; GENNARI, S.M.; MINERVINO, N.A.;FARIAS, N.A.R.; RUAS, J.L.; SANTOS, T.R.B.; CAVALCANTE, G.T.; KWOK, O.C.H.; SU, C. Biologic and genetic comparison of Toxoplasma gondii isolates in free-range chickens from the northern Pará state and the southern state Rio Grande do Sul, Brazil revealed highly diverse and distinct parasite populations. Veterinary Parasitology. Artigo in Press, 2006.

DUBEY, J.P; VENTURINI, M.C.; VENTURINI, L.;PISCOPO, M.; GRAHAM, D.H.; DAHI, E.; SREEKUMAR, C.; VIANNA, M.C.; LEHMANN, T. Isolation al., 2003; Frazão-Teixeira et al., 2006) e derivados de animais (Dias et al., 2005). Assim, a alta soroprevalência de anticorpos específicos para o Toxoplasma, em ambas as espécies em Santa Rita de Cássia, associada ao hábito humano de ingerir carne crua ou mal cozida, pode ser considerada uma importante fonte de infecção na comunidade estudada.

Os resultados desta pesquisa sugerem que tanto os suínos quanto os frangos podem estar envolvidos na transmissão da protozoose da região. Além disso, a prevalência da infecção por T.gondii nestes animais pode servir como parâmetro para se traçar metas de ações profiláticas em regiões rurais, principalmente quando associadas à clínica e às características ambientais e populacionais, pois podem detectar os diversos fatores de risco à comunidade.

and genotyping of Toxoplasma gondii from free-ranging chickens from Argentina. Journal of Parasitology, v. 89, n. 5, p.1063-1064, 2003.

FIALHO, C.G.; ARAUJO, F.A.P. Detecção de anticorpos para Toxoplasma gondii em soro de suínos criados e abatidos em frigoríficos da região da grande Porto Alegre - RS, Brasil. Ciência Rural, Santa Maria, v. 33, n. 5, p. 893-897, 2003.

FRAZÃO-TEIXEIRA E.; OLIVEIRA F.C.R.; PELISSARI-SANT'ANA V.; LOPES C.W.G. Toxoplasma gondii em encéfalos de suínos comercializados no município de Campos dos Goytacazes, estado do Rio de Janeiro, Brasil. Revista Brasileira de Parasitologia Veterinária, v. 15, n. 1, p. 33-36, 2006.

GARCIA, J. L.; NAVARRO, I. T.; OGAWA, L.; OLIVEIRA, R. C. Soroprevalência do Toxoplasma gondii em suínos, bovinos, ovinos e eqüinos e sua correlação com humanos, felinos e caninos, oriundos de propriedades rurais do norte do Paraná, Brasil. Ciência Rural, Santa Maria, v. 29, n. 1, p. 91-97, 1999.

GARCIA, J.L.; NAVARRO, L.; OLIVEI, I.T.; OGAWA RA, R.C.; MARANA, E.R.M. Soroprevalência do Toxoplasma gondii em galinhas (Gallus gallus domesticus) de criações domésticas, oriundas de propriedades rurais do norte do Paraná, Brasil. Ciência Rural, Santa Maria, v. 30, n. 1, p. 123-127, 2000.

GOLDMAN, M. Staining Toxoplasma gondii with fluorescein labeled antibody. II - A new serologic test for antibodies to Toxoplasma based upon inhibition of specific staining. The Journal of Experimental Medicine v. 105, p. 557-573, 1957.

KANETO, C.N.; COSTA, A.J.; PAULILLO, A.C.; MORAES, F.R.; MURAKAMI, T.O.; MEIRELES, M.V. Experimental toxoplasmosis im broiler chicks. Veterinary Parasitology, v. 69, p. 103-110, 1997.

KRICK, J.A.; REMINGTON, J.S. Current concepts in parasitology. Toxoplasmosis in the adult - An Overview. The New England Journal of Medicine, v. 9, p. 550-553, 1978.

REMINGTON, J.S.; KLEIN, J. O. Infections diseases of the fetus and newborn infant. Fifth edition. 2001. Capítulo 5: Toxoplasmosis. Remington, JS; McLeod, R; Desmonts, G. p. 140-267.

SABIN, A.B. Biological and immunological identity of Toxoplasma of animal and human origin. Proceedings of the Society for Experimental Biology and Medicine v. 41, p. 75-80, 1939.

SMITH, H.J. Seroprevalence of anti-toxoplasma lgG in Canadian swine. Canadian journal of veterinary research. Canadá: Canadian Veterinary Medical Association. v. 55, p. 380-381, 1991.

TENTER, A. M.; HECKEROTH, A. R.; WEISS, L. M. Toxoplasma gondii: from animals to humans. International Journal for Parasitology. United Kindom: Elsevier Science B.V., v. 30, p. 1217-1258, 2000.

VENTURINI, M.C.; BACIGALUPE, D.; VENTURINI, L.; RAMBEAUD, M.; BASSO, W.; UNZAGA, J.M.; PERFUMO, C.J. Seroprevalence of Toxoplasma gondiifrom slaughterhouses and in pigs from an indoor and an outdoor farm in Argentina. Veterinary Parasitology. v. 124, p. 161-165, 2004. 